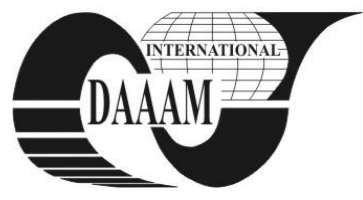

Annals of DAAAM for 2011 \& Proceedings of the 22nd International DAAAM Symposium, Volume 22, No. 1, ISSN 1726-9679 ISBN 978-3-901509-83-4, Editor B. Katalinic, Published by DAAAM International, Vienna, Austria, EU, 2011 Make Harmony between Technology and Nature, and Your Mind will Fly Free as a Bird Annals \& Proceedings of DAAAM International 2011

\title{
DENTAL IMPLANT-ABUTMENT CONNECTION TOPOLOGY - FEA INVESTIGATIONS
}

\author{
DUSE, D[an] - M[aniu] \& PASA, A[lexandru]
}

\begin{abstract}
Regarding the abutment-implant connection of screw shaped dental implants, the recent studies generally compare the conical and planar ones. The current research aims at improving the abutment-implant connection, from the topological point of view, in order to lower the stresses in the implant body and lower the abutment displacement. The reference shape upon all investigated connections were built is the conical internal one. Therefore, the following connection shapes were studied: external conical, internal conical, concave, convex, concave-convex and convex-concave.
\end{abstract}

Key words: FEA, dental, implant, abutment, connection

\section{INTRODUCTION}

The first abutment-implant connections of, the two piece screw shaped dental implants were planar, which led to high abutment displacements during functioning. The introduction of the internal conical connection provided a better sealing and stress distribution between abutment and implant body, as well as the self-guiding of the abutment. As shown in (Wierszycki et al., 2006), the implant-abutment contact surface plays an important role in the implant's lifecycle, influencing directly its behaviour to fatigue loading. The current study investigates alternative connection shapes to the conical one, from the topological point of view, in order to improve stress distribution and values in the implant body and to lower the abutment displacement under load.

\section{MATERIALS AND METHODS}

The analyses are run in ABQUS, according to the ISO 14801:2007 testing layout, but in static case, with an approach of $4 \mathrm{~mm} / \mathrm{step}$ of the loading device (Fig. 1). The implant model used has a $4,5 \mathrm{~mm}$ diameter, $10 \mathrm{~mm}$ length and bullet shape. The thread was omitted, in order to simplify the model (Kong et al., 2009). As this is a topological investigation, no dimensional analysis is conducted, the connection's shape being the only variable of the study. All connections - conical external (ex.co), concave (cc), convex (cv), concave-convex (cc-cv) and convexconcave (cv-cc) (Fig. 3 and Fig. 7) - are built around an internal conical one (int.co), which was considered the reference shape for all analysed models. The selection of the alternative connections was made on the premises that in order to decrease the stresses in the implant, and implicitly in the bone, the implant-abutment contact surface has to bee increased (Bendsoe \& Sigmund, 2004). The other criteria on which the above mentioned shapes were chosen are manufacturing costs, production capabilities and implant-abutment sealing.

The research was conducted in two phases. First, the internal and external conical connections were compared to the concave and convex ones. Next, based on the outcome of the analysis, the authors attempted to further improve the results.

The parts used in the tests are presented in Fig. 1. The materials applied to the parts are presented in Tab. 1. (Leyens \& Peters, 2003).

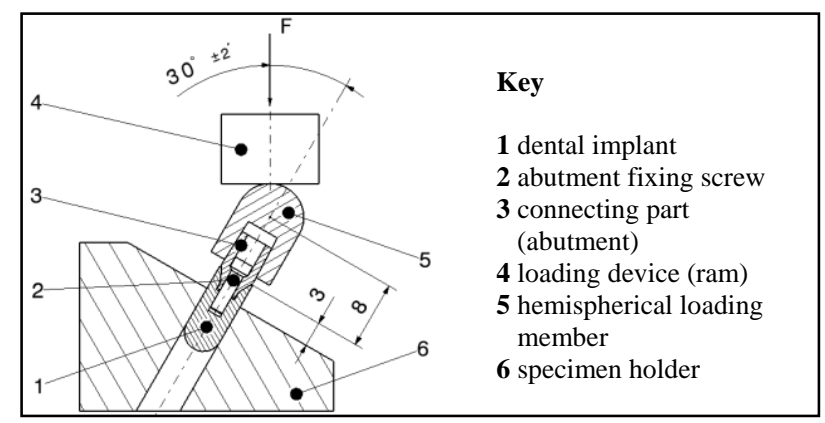

Fig. 1. Assembly model and loading schematics

\begin{tabular}{|c|c|c|c|c|c|c|c|}
\hline $\begin{array}{c}\text { Part } \\
\text { No. }\end{array}$ & Material & $\begin{array}{c}\text { Material } \\
\text { type }\end{array}$ & $\begin{array}{c}\mathrm{E} \\
{[\mathrm{Mpa}]}\end{array}$ & $\begin{array}{c}\mathrm{Rm} \\
{[\mathrm{Mpa}]}\end{array}$ & $\begin{array}{c}\mathrm{v} \\
{[-]}\end{array}$ & $\begin{array}{c}\mathrm{Rp} 0,2 \\
{[\mathrm{Mpa}]}\end{array}$ & $\begin{array}{c}\mathrm{A} \\
{[\%]}\end{array}$ \\
\hline $1,2,3$ & Ti6Al4V & $\begin{array}{c}\text { Elastic } \\
\text { Plastic }\end{array}$ & 113800 & 1138 & 0.342 & 1069 & 14 \\
\hline 5 & Steel & Elastic & 210000 & - & 0,3 & - & - \\
\hline
\end{tabular}

Tab. 1. Material properties of the parts used in the analyses

The loading device (4) and specimen holder (6) are considered to be analytical rigid bodies ( 0 deformations). The friction coefficient used between the parts in contact is 0,1 (except for tied contacts).

The testing of each implant model was done as follows: an $820 \mathrm{~N}$ tightening load was applied on the abutment fixing screw and a $500 \mathrm{~N}$ test load was applied on the loading device.

The safety factor used in the analyses is 1,2 , therefore resulting in an acceptable stress limit of $880 \mathrm{MPa}$ for the Ti6Al4V parts.

\section{RESULTS}

\subsection{Phase I}

The connection shapes analysed in the first phase of the research are presented in Fig. 3.

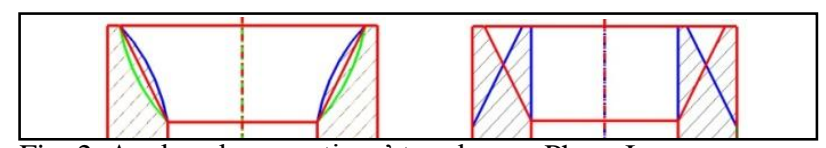

Fig. 2. Analysed connections' topology - Phase I

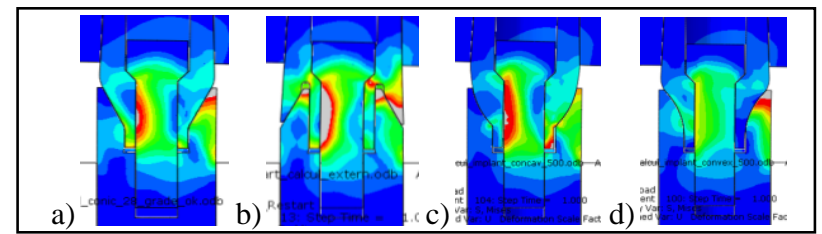

Fig. 3. Stress distribution in the models' fixing screws a) int.co; b) ex.co; c) cc; d) cv

According to Fig. 4 b), the stresses in the external conical connection fixing screw are too high and the influenced area too big, for it to be a viable option for the current research. 


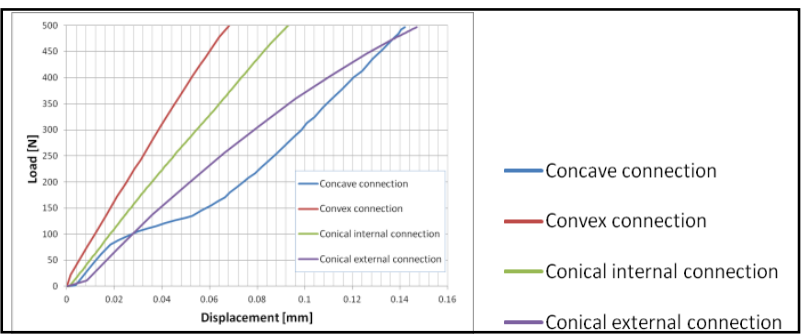

Fig. 4. Load-displacement graphic of the analysed models

The load-displacement curve was also generated for the ext.co model, for comparison purposes.

The maximum stresses in the implant bodies, after the loading step, are presented in Fig. 6: 1053,6MPa (int.co)(a), $1070,8 \mathrm{MPa}$ (ext.co)(b), $765 \mathrm{MPa}(\mathrm{cc})(\mathrm{c})$ and $881 \mathrm{MPa}(\mathrm{cv})(\mathrm{d})$. a)

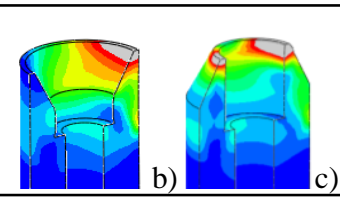

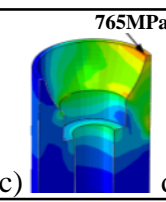
s' implant bodies

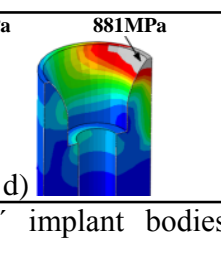

\subsection{Phase II}

Further on, the authors are trying to combine the low stresses resulted from the use of the concave connection, with the high stability of the convex one (Fig. 7), resulting in the concave-convex and convex-concave connection shapes. Also, the abutment fixing screw diameter of the concave connection model is shrunk in the area where the abutment comes in contact with it, in order to observe if the displacement of the abutment is low enough as not to overload the screw.

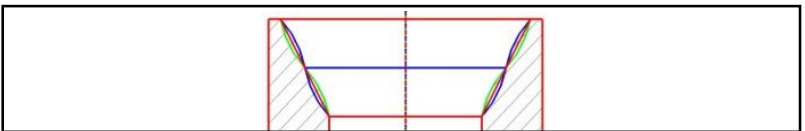

Fig. 6. Analysed connections' topology - Phase II

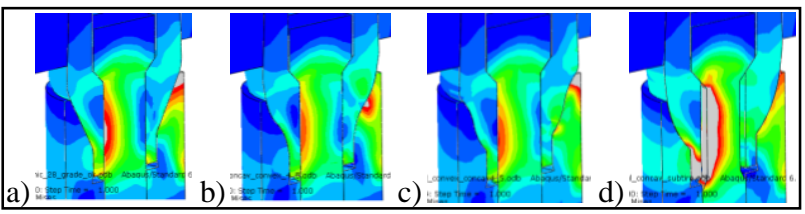

Fig. 7. Stress distribution in the models' fixing screws a) int.co; b)cc-cv; c) cv-cc; d) cc (modified)

According to Fig. 8, the stresses in the new concave connection fixing screw are too high and the influenced area is too big for it to be a viable option for the current research. However, the load-displacement curve will be generated for this model also, for comparison purposes.

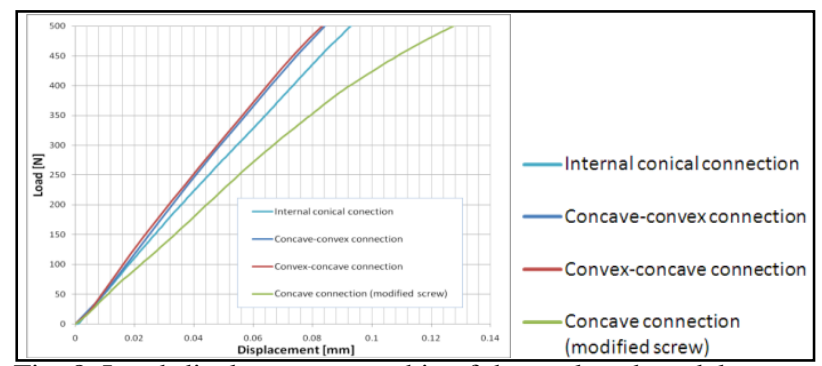

Fig. 8. Load-displacement graphic of the analysed models

The maximum stresses present in the implant bodies, after the loading step, are presented in Fig.10: 1053,6MPa (int.co)(a), 942,6MPa (cc-cv)(b) and 1069,8MPa (cv-cc)(c).

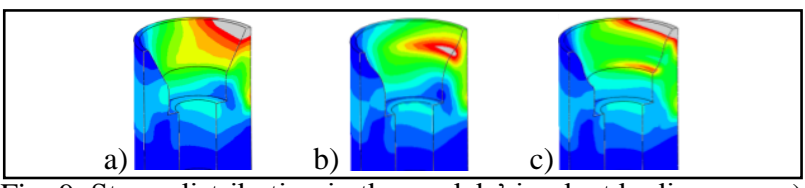

Fig. 9. Stress distribution in the models' implant bodies a) int.co; b) $\mathrm{cc}-\mathrm{cv}$; c) cv-cc

\section{CONCLUSIONS}

Fig. 11 shows the load-displacement behaviour of all models analysed in the present research.

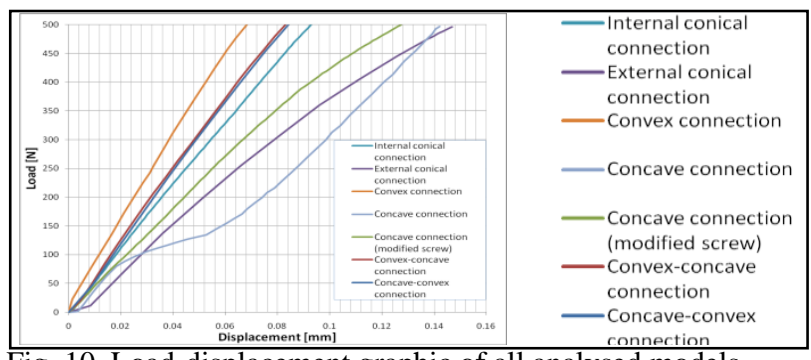

Fig .10. Load-displacement graphic of all analysed models

According to Fig.11, the connections which present the best behaviour, from the stress (value and distribution) and displacement points of view, are presented in Tab.2.

\begin{tabular}{|l|c|c|c|}
\hline Connection shape & Int.co & $C v$ & $C c-c v$ \\
\hline Max. system displacement [mm] & $\sim 0,09$ & $\sim 0,07$ & $\sim 0,08$ \\
\hline Max. implant stress [MPa] & $\sim 1054$ & $\sim 881$ & $\sim 943$ \\
\hline Max. screw stress [MPa] & $>880$ & $\sim 660$ & $\sim 733$ \\
\hline Manufacturing difficulty & Medium & High & Very high \\
\hline Implant-abutment sealing & Very good & nav & nav \\
\hline
\end{tabular}

Key: nav - no available data

Tab. 2. Best concluded connections comparison

From a strictly topological point of view, the research shows that the convex connection is superior, displacements and stresses distribution and value wise, to all other connection shapes analysed in the current study.

\section{ACKNOWLEDGEMENTS}

Research developed within the POSDRU/6/1.5/S/26 project, co-financed by The Development of Human Resources Sectorial Operational Program 2007-2013, from the European Social Fund.

Research developed within the Lucian Blaga University, Sibiu, Romania, PhD. programs.

\section{REFERENCES}

Bendsoe, M. P. \& Sigmund O. (2004). Topology Optimization Theory, Methods and Applications, Springer, ISBN: 3-54042992-1, Berlin, Germany

Kong, L., Zhao, Y.; Hua, K.; Li, D.; Zhou, H.; Wuc, Z. \& Liu, B. (2009). Selection of the implant thread pitch for optimal biomechanical properties: A three-dimensional finite element analysis. Advances in Engineering Software, Vol. 40, No 7, (July 2009) pp. 474-478, ISSN: 0965-9978

Leyens, C. \& Peters, M. (2003). Titanium and Titanium Alloys, Wiley-VCH GmbH \& Co. KGaA, ISBN: 3-527-30534-3, Weinheim, Germany

Wierszycki, M.; Kąkol, W. \& Lodygowski, T. (2006). The Screw Loosening and Fatigue Analyses of Three Dimensional Dental Implant Model, Proceedings of the ABAQUS Users' Conference 2006, ABAQUS Inc., May 2006, Rhode Island, USA, pp. 527-541

*** (2005) ABAQUS Analysis User's Manual, ABAQUS Inc. Pawtucket, 2005 